Article

\title{
Terpenoids and Bibenzyls from Three Argentine Liverworts
}

\section{Fumihiro Nagashima * and Yoshinori Asakawa}

Faculty of Pharmaceutical Sciences, Tokushima Bunri University, Yamashiro-cho, Tokushima 770-8514, Japan; E-Mail: asakawa@ph.bunri-u.ac.jp (Y.A.)

* Author to whom correspondence should be addressed; E-Mail: fnaga@ph.bunri-u.ac.jp; Tel.: +81-88-602-8450; Fax: +81-88-655-3051.

Received: 22 November 2011; in revised form: 5 December 2011 / Accepted: 12 December 2011 / Published: 16 December 2011

\begin{abstract}
A new rosane diterpenoid, 3 $\alpha$-hydroxy-5,15-rosadien-11-one (3), was isolated, together with a known rosane diterpenoid, 5,15-rosadiene-3,11-dione (4), and an aromadendrane sesquiterpenoid, ent-cyclocolorenone (5), from the $\mathrm{Et}_{2} \mathrm{O}$ extract of an unidentified Argentine liverwort Anastrophyllum species. Moreover, four known sesquiterpene lactones 6-9 and two known bibenzyls 10, 11 were isolated from the $\mathrm{Et}_{2} \mathrm{O}$ extracts of Argentine Frullania brasiliensis and Radula voluta, respectively. The structures of compounds 3-11 were determined by the use of NMR techniques.
\end{abstract}

Keywords: Jungermanniales; liverwort; Radula voluta; Frullania brasiliensis; Anastrophyllum species; bibenzyl; rosane; chemosystematics

\section{Introduction}

Due to their small morphology, liverworts (Hepaticae) are difficult to classify and identify. However, they are a rich source of terpenoids and aromatic compounds, which can be used to evaluate their chemosystematics [1,2]. In our search for new biologically active substances, we continue to study the chemical constituents of liverworts. Many liverworts are endemic to the southern hemisphere, including Oceania and South America. Recently, we have reported the structures of new sesqui- and diterpenoids from New Zealand liverworts [3]. We also reported the isolation of new sesquiterpenoids 1 and 2 from an unidentified Gackstroemia species from New Zealand [4]. During the course of our investigation of the chemical constituents of three Argentine Jungermanniales species (unidentified Anastrophyllum species, Radula voluta and Frullania brasiliensis), we isolated a new 
rosane diterpenoid $\mathbf{3}$ and six previously known compounds: Rosane 4, aromadendrane 5, two eudesmanes 6 and 7, two eremophilanes 8 and 9, and two bibenzyls 10 and 11 (Figure 1) and characterized their chemical structures. The chemosystematics of these three species from Argentina are discussed.

Figure 1. Terpenoids and bibenzyls isolated from Argentine liverworts.<smiles>C=C(C)[C@H]1C=C2C(C)CC[C@@H](O)[C@H]2CC1</smiles>

1<smiles></smiles>

5<smiles>C=C1C(=O)O[C@H]2[C@@H]1CCC1=CCCC(C)C12C</smiles>

9

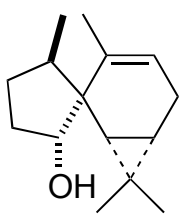

2<smiles>C=C1C(=O)O[C@H]2C1=C(C)CCCC2(C)C</smiles>

6

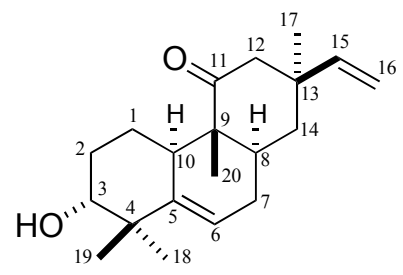

3

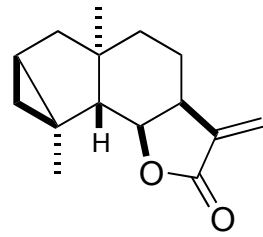

7



4<smiles>CC1CCC=C2CC[C@@H]3[C@@H](C)C(=O)O[C@H]3C21C</smiles>

8<smiles>CC(C)=CCC/C(C)=C/Cc1c(O)cc(O)cc1CCc1ccccc1</smiles>

\section{Results and Discussion}

The new rosane diterpenoid 3 was isolated from the ether extract of an unidentified Anastrophyllum species by chromatographic separation (silica gel and Sephadex LH-20), together with ent-cyclocolorenone (5) [5] and 5,15-rosadiene-3,11-dione (4) [6], whose spectral and physical data were identical with those of authentic samples.

The mass spectrum of 3 showed $m / z 302[\mathrm{M}]^{+}$and its molecular formula, $\mathrm{C}_{20} \mathrm{H}_{30} \mathrm{O}_{2}$ (calcd. 302.2245), was confirmed by HR-EIMS. The IR spectrum demonstrated the presence of hydroxy and carbonyl groups. The ${ }^{1} \mathrm{H}-\mathrm{NMR}$ spectrum (Table 1$)$ of $\mathbf{3}$ showed the signals of terminal vinyl protons $(\delta 4.94 d d$, $4.96 d d, 5.83 d d)$, an olefinic proton $(\delta 5.56 d)$, a proton $(\delta 3.23 d d)$ on a carbon bearing a hydroxy group and four tertiary methyls. The ${ }^{13} \mathrm{C}-\mathrm{NMR}$ spectrum (Table 2 ) exhibited 20 carbons, and its DEPT spectrum indicated the presence of trisubstituted olefinic carbons ( $\delta 117.0 d, 145.5 s)$, terminal vinyl carbons $(\delta 110.2 t, 147.9 d)$, a carbonyl carbon $(\delta 214.7)$ and a methine $(\delta 77.2)$ with a hydroxy group, together with four methyls, four methylenes, two methines and three quaternary carbons. Since the 
${ }^{13} \mathrm{C}$-NMR (Table 2) data was similar to those of the 5,15-rosadiene-3,11-dione (4) [6], compound 3 was suggested to be a rosane diterpenoid.

Table 1. ${ }^{1} \mathrm{H}-\mathrm{NMR}$ data of $3\left(600 \mathrm{MHz}, \mathrm{CDCl}_{3}\right)^{\mathrm{a}}$.

\begin{tabular}{|c|c|c|c|}
\hline $\mathbf{H}$ & & $\mathbf{H}$ & \\
\hline 1 & $\begin{array}{l}1.01 \mathrm{~m} \\
1.97 \mathrm{~m}\end{array}$ & 14 & $\begin{array}{l}1.36 \mathrm{dd}(10.2,2.5) \alpha \\
1.76 \mathrm{~m} \beta\end{array}$ \\
\hline 2 & $\begin{array}{l}1.69 \mathrm{~m} \\
1.78 \mathrm{~m}\end{array}$ & 15 & $5.83 \mathrm{dd}(17.3,10.7)$ \\
\hline 3 & $3.23 \mathrm{dd}(11.5,4.7)^{\mathrm{b}}$ & 16 & $\begin{array}{l}4.94 \mathrm{dd}(10.7,0.8) \\
4.96 \mathrm{dd}(17.3,0.8)\end{array}$ \\
\hline 6 & $5.56 \mathrm{~d}(6.3)$ & 17 & $0.97 \mathrm{~s}$ \\
\hline 7 & $\begin{array}{l}1.87 \mathrm{~m} \\
1.98 \mathrm{~m}\end{array}$ & 18 & $0.99 \mathrm{~s}$ \\
\hline 8 & $1.77 \mathrm{~m}$ & 19 & $1.15 \mathrm{~s}$ \\
\hline 10 & $2.72 \mathrm{~m}$ & 20 & $0.98 \mathrm{~s}$ \\
\hline 12 & $\begin{array}{l}1.95 \mathrm{dd}(12.6,2.5) \alpha \\
2.73 \mathrm{~d}(12.6) \beta\end{array}$ & & \\
\hline
\end{tabular}

Table 2. ${ }^{13} \mathrm{C}-\mathrm{NMR}$ of $\mathbf{3}$ and $\mathbf{4}\left(100 \mathrm{MHz}, \mathrm{CDCl}_{3}\right)^{\mathrm{a}}$.

\begin{tabular}{|c|c|c|c|c|c|}
\hline $\mathbf{C}$ & $\mathbf{3}$ & $\mathbf{4}[6]$ & $\mathbf{C}$ & $\mathbf{3}$ & $\mathbf{4}[6]$ \\
\hline 1 & 25.3 & 25.2 & 11 & 214.7 & 214.4 \\
2 & 30.3 & 37.8 & 12 & 48.4 & 48.5 \\
3 & 77.2 & 214.6 & 13 & 41.6 & 41.6 \\
4 & 42.1 & 51.0 & 14 & 38.4 & 38.4 \\
5 & 145.5 & 144.2 & 15 & 147.9 & 147.7 \\
6 & 117.0 & 118.2 & 16 & 110.2 & 110.4 \\
7 & 28.9 & 29.0 & 17 & 23.5 & 23.5 \\
8 & 38.3 & 38.2 & 18 & 21.4 & 22.7 \\
9 & 48.9 & 49.4 & 19 & 24.4 & 29.5 \\
10 & 37.9 & 38.6 & 20 & 12.7 & 12.0 \\
\hline \multicolumn{5}{|c}{ Chemical shift values are in $\delta(\mathrm{ppm})}$.
\end{tabular}

The ${ }^{1} \mathrm{H}_{-}{ }^{1} \mathrm{H}$ COSY of 3 confirmed three partial segments: (A) $-\mathrm{CH}(\mathrm{OH})-\mathrm{CH}_{2}-\mathrm{CH}_{2}-\mathrm{CH}-$, (B) $-\mathrm{CH}_{2}-$ $\mathrm{CH}-\mathrm{CH}_{2}-\mathrm{CH}=\mathrm{C}-$, and $(\mathrm{C})-\mathrm{CH}=\mathrm{CH}_{2}$. As seen in the $\mathrm{HMBC}$ spectrum (Figure 2), the tertiary methyl at $\mathrm{H}-17$ correlated with the methylene carbon at $\mathrm{C}-4$ in segment $\mathrm{B}$, the terminal vinyl carbon at $\mathrm{C}-15$, the quaternary carbon at $\mathrm{C}-13$ and the isolated methylene carbon at $\mathrm{C}-12$, methylene protons at $\mathrm{H}-12$ of which correlated with the carbonyl carbon at C-11. The other tertiary methyl at H-20 correlated with the methine at $\mathrm{C}-10$ in segment $\mathrm{A}$, the carbonyl carbon, the quaternary carbon at C-9 and the aliphatic methine in segment $\mathrm{B}$. The methyl groups at $\mathrm{H}-18$ and 19 correlated with the methine at $\mathrm{C}-3$ bearing hydroxy group in segment $\mathrm{A}$, an aliphatic quaternary carbon and a trisubstituted olefinic quaternary carbon. On the basis of the above results, the structure of 3 was elucidated to be 3-hydroxy-5,15rosadien-11-one. The stereochemistry of $\mathbf{3}$ was clarified by the NOESY spectrum of the $m$-bromobenzoate derivative $\mathbf{1 2}$ of $\mathbf{3}$. NOE correlations (Figure 3) of $\mathbf{1 2}$ were observed between: 
(i) $\mathrm{H}-3$ and $\mathrm{H}-1 \beta, \mathrm{H}-18$; (ii) $\mathrm{H}-1 \beta$ and $\mathrm{H}-20$; (iii) $\mathrm{H}-20$ and $\mathrm{H}-7 \beta, \mathrm{H}-12 \beta, \mathrm{H}-14 \beta$; (iv) $\mathrm{H}-19$ and $\mathrm{H}-10$; (v) H-10 and H-8; (vi) H-8 and H-17. Moreover the CD spectrum of $\mathbf{3}$ showed a positive Cotton effect $\left(\lambda_{\max } 297\right)$ as the same Cotton effect $\left(\lambda_{\max } 298\right)$ as 4 [6]. Thus, the structure of 3 was shown to be $3 \alpha$-hydroxy-5,15-rosadien-11-one. However, the absolute configuration of $\mathbf{3}$ has not yet clarified because the use of only the Cotton effect of the CD spectrum was not able to establish it unequivocally.

Figure 2. ${ }^{1} \mathrm{H}-{ }^{1} \mathrm{H}$ (bold line) and long range ${ }^{1} \mathrm{H}-{ }^{13} \mathrm{C}$ (arrows) correlations of 3.

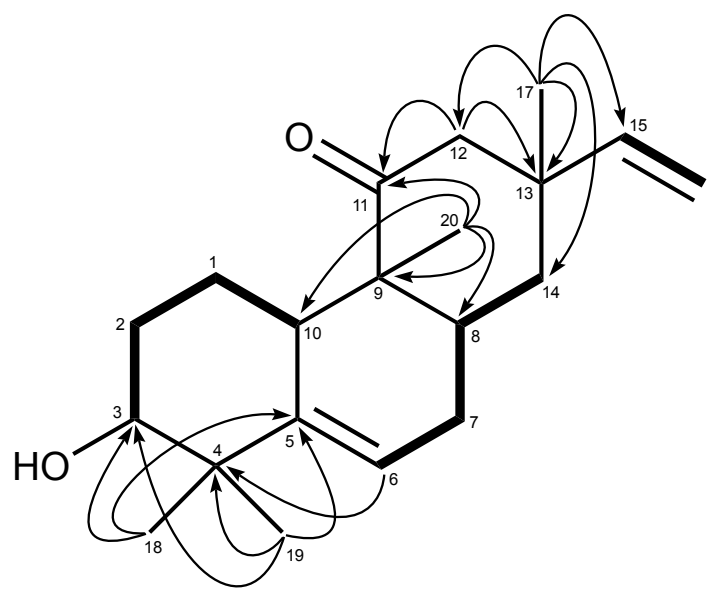

Figure 3. NOE correlations of $\mathbf{1 2}$.

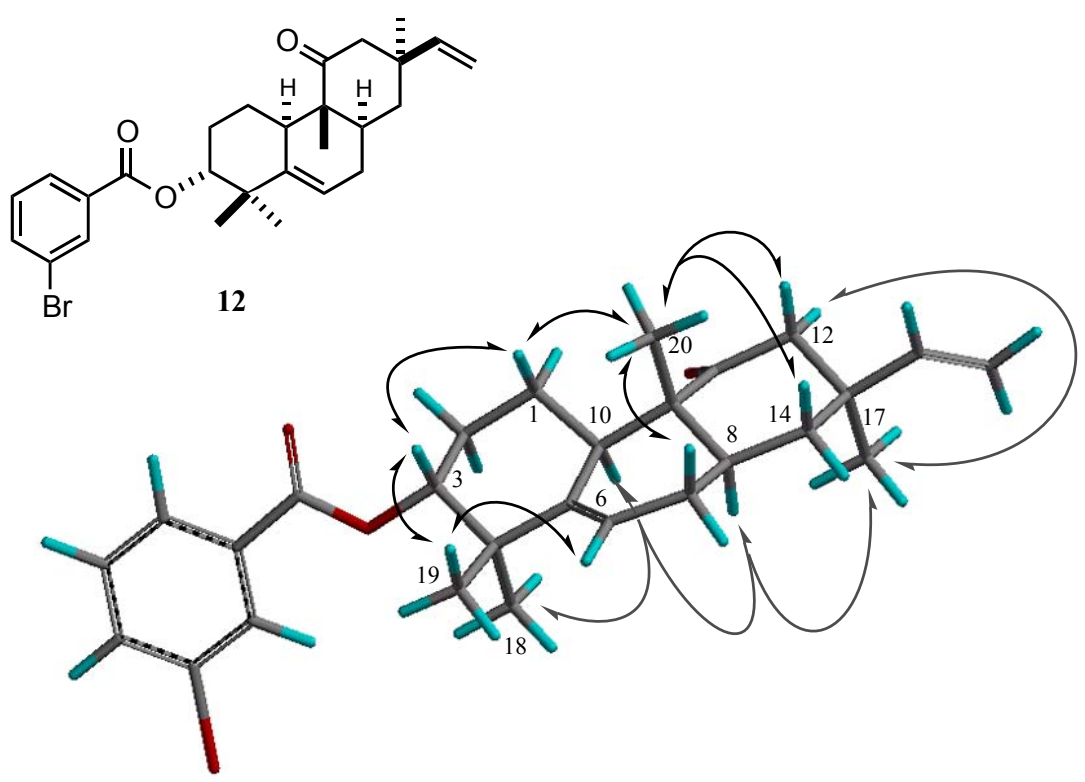

Frullania brasiliensis contains sesquiterpene lactones [7]. We reexamined the same species for the purpose of potentially isolating new compounds. A chromatographic separation of the ether extract of Frullania brasiliensis resulted in the isolation of two eudesmanes, (+)-frullanolide (6), which causes potent allergenic contact dermatitis [8], and nepalensolide A (7) [9], and two eremophilanes, 5-epi-dilatanolide A (8) [7] and 5-epi-dilatanolide B (9) [7]. 
Two bibenzyl compounds, 3,5-dihydroxy-2-(3-methyl-2-butenyl)bibenzyl (10) [10,11] and 2-geranyl-3,5-dihydroxybibenzyl (11) [12], were chromatographically isolated from the ether extract of Radula voluta.

Fusicoccane and sphenolobane diterpenoids are common chemical components isolated from Anastrophyllum species, e.g., from A. minutum [13], A. aurztum [14] and A. donnianum [15]. These diterpenoids are very characteristic for Anastrophyllum genus belonging to the Jungermanniaceae. However, neither sphenolobane nor fusicoccane were isolated from the present unidentified Anastrophyllum species. Those isolates included naturally rare rosane diterpenoid and aromadendrane sesquiterpenoid. Therefore, the unidentified Anastrophyllum species may be from a chemically different taxon from the other Anastrophyllum species.

Eudesmane and eremophilane sesquiterpene lactones have been isolated from $F$. brasiliensis (Frullaniaceae) [7] and are considered the most important chemical markers of the Frullaniaceae [1,2,16]. The present $F$. brasiliensis also contained the same eudesmanolides and eremophilanolides as those reported.

A number of bibenzyls and prenyl bibenzyls were isolated from European, New Zealand, Ecuador and Japanese Radula species (Radulaceae) [1,2,17]. R. voluta also produced bibenzyls $\mathbf{1 0}$ and 11, which are ubiquitous components in the Radula species. The Radula including $R$. voluta is chemically very isolated from the other liverworts examined so far, since the presence of terpenoids is very rare.

\section{Experimental}

\subsection{General}

${ }^{1} \mathrm{H}$ and ${ }^{13} \mathrm{C}$-NMR: 200, 400 and $600 \mathrm{MHz}\left({ }^{1}-\mathrm{NMR}\right)$ and 100, $150 \mathrm{MHz}\left({ }^{13} \mathrm{C}-\mathrm{NMR}\right)$. Chemical shift values were expressed in $\delta$ (ppm) downfield from tetramethylsilane as an internal standard $\left({ }^{1} \mathrm{H}-\mathrm{NMR}\right)$ and $\delta 77.03(\mathrm{ppm})$ from $\mathrm{CDCl}_{3}$ as a standard $\left({ }^{13} \mathrm{C}-\mathrm{NMR}\right)$. TLC: Visualized under UV (254 nm) light and by spraying with $10 \% \mathrm{H}_{2} \mathrm{SO}_{4}$ or Godin reagent [18] followed by heating at $120-130{ }^{\circ} \mathrm{C} . \mathrm{MeOH}-$ $\mathrm{CH}_{2} \mathrm{Cl}_{2}$ (1:1) was used for Sephadex LH-20. [ $\left.\alpha\right]_{\mathrm{D}}$ : $\mathrm{CHCl}_{3}$. Radula voluta Tayl. ex Gott., Lindenb. \& Nees, Frullania brasiliensis Raddi and unidentified Anastrophyllum species were collected in Argentina in 2005 and identified by Prof. Dr. S. R. Gradstein (University of Göttingen, Germany). The voucher specimen was deposited at the Institute of Pharmacognosy, Tokushima Bunri University.

\subsection{Extraction and Isolation}

The dry material (14.7 g) of the unidentified Anastrophyllum species was ground and extracted with $\mathrm{Et}_{2} \mathrm{O}$. The crude extract (471.4 mg) was divided into 10 fractions by column chromatography on silica gel ( $n$-hexane-EtOAc gradient). Fraction 4 gave ent-cyclocolorenone $(5)\left([\alpha]_{\mathrm{D}}+376.9^{\circ} c 1.45 ; 15.6 \mathrm{mg}\right)$ and 5,15-rosadiene-3,11-dione (4) $(6 \mathrm{mg})$ by rechromatography on silica gel ( $n$-hexane-EtOAc 17:3, $\mathrm{CH}_{2} \mathrm{Cl}_{2}-\mathrm{Et}_{2} \mathrm{O}$ 49:1). 3 $\alpha$-Hydroxy-5,15-rosadien-11-one (3) (4.5 mg) was purified from Fraction 6 by Sephadex LH-20 and silica gel ( $n$-hexane-EtOAc 19:1).

The crude $\mathrm{Et}_{2} \mathrm{O}$ extract (1.9 g) of $F$. brasiliensis (90.8 g) was chromatographed on silica gel ( $n$-hexane-EtOAc gradient) to give six fractions. Fraction 3 was rechromatographed on Sephadex LH-20, silica gel ( $n$-hexane-EtOAc or $n$-hexane-Et ${ }_{2} \mathrm{O}$ ), MPLC (Si-60, toluene) and prep. HPLC (Cosmosil 5SL-II, $n$-hexane-Et ${ }_{2} \mathrm{O}$ 98:2) to give (+)-frullanolide (6) (59.3 mg) and nepalensolide A (7) 
(15.1 mg). 5-Epi-dilatanolide A (8) (13.9 mg) and 5-epi-dilatanolide B (9) (5.4 mg) were isolated from Fraction 5 by a combination of reverse phase silica gel $\left(\mathrm{CH}_{3} \mathrm{CN}\right)$, MPLC $\left(\mathrm{Si}-60, n\right.$-hexane-Et $\left.\mathrm{O}_{2} \mathrm{O} 4: 1\right)$ and prep. HPLC (UK-silica, $n$-hexane-EtOAc 9:1).

The dry material $\left(690 \mathrm{mg}\right.$ ) of $R$. voluta was ground and extracted with $\mathrm{Et}_{2} \mathrm{O}$. The crude extract (79 $\mathrm{mg}$ ) was chromatographed on Sephadex LH-20 and silica gel to give 3,5-dihydroxy-2-(3-methyl-2butenyl)bibenzyl (10) (17.6 mg) and 2-geranyl-3,5-dihydroxybibenzyl (11) (3.1 mg).

3 $\alpha$-Hydroxy-5,15-rosadien-11-one (3): $[\alpha]_{\mathrm{D}}+71.3^{\circ}$ (c 1.31); CD (EtOH): $\Delta \varepsilon_{297 \mathrm{~nm}}+1.70, \Delta \varepsilon_{211 \mathrm{~nm}}-0.51$ $\left(c=9.77 \times 10^{-4}\right)$; FTIR $v_{\max } \mathrm{cm}^{-1}: 3438,1704 ;{ }^{1} \mathrm{H}-\mathrm{NMR}$ see Table 1; and ${ }^{13} \mathrm{C}-\mathrm{NMR}$ see Table 2; HR-EIMS: calcd for $\mathrm{C}_{20} \mathrm{H}_{30} \mathrm{O}_{2}$ : 302.2245. Found: 302.2253; EIMS $\mathrm{m} / \mathrm{z}$ (rel. int.): $302[\mathrm{M}]^{+}(10)$, 284(100), 269(47), 241(76), 226(11), 211(11), 201(11), 187(47), 173(47), 171(46), 159(23), 151(34), 145(21), 134(27), 119(26), 105(29), 91(25), 79(113), 67(11), 55(13), 41(15).

m-Bromobenzoate 12: To compound $3(3.5 \mathrm{mg})$ in dry $\mathrm{CH}_{2} \mathrm{Cl}_{2}(2 \mathrm{~mL})$ was added $m$-bromobenzoic acid (5 mg), DCC (4 mg) and DMAP ( $2 \mathrm{mg}$ ) and the solution was stirred at r.t. overnight. The reaction mixture was filtered and chromatographed on silica gel ( $n$-hexane-EtOAc 19:1) to yield $m$-bromobenzoate $12(4.2 \mathrm{mg}) .{ }^{1} \mathrm{H}-\mathrm{NMR}\left(600 \mathrm{MHz}, \mathrm{CDCl}_{3}\right): \delta 8.17(1 \mathrm{H}, t, J=1.9 \mathrm{~Hz}), 7.98(1 \mathrm{H}, d d$, $J=8.0,1.1 \mathrm{~Hz}), 7.69(1 \mathrm{H}, d d d, J=8.0,1.9,1.1 \mathrm{~Hz}), 7.33(1 \mathrm{H}, t, J=8.0 \mathrm{~Hz}), 2.05(1 \mathrm{H}, m, \mathrm{H}-1 \alpha), 1.16$ $(1 \mathrm{H}, d d, J=12.9,4.1 \mathrm{~Hz}, \mathrm{H}-1 \beta), 1.82-1.95(3 \mathrm{H}, m, \mathrm{H}-2, \mathrm{H}-2, \mathrm{H}-7 \alpha), 4.73(1 \mathrm{H}, d d, J=11.3,4.7 \mathrm{~Hz}$, $\mathrm{H}-3), 5.62(1 \mathrm{H}, d, J=6.3 \mathrm{~Hz}, \mathrm{H}-6), 1.99(1 \mathrm{H}, m, \mathrm{H}-7 \beta), 1.80(1 \mathrm{H}, m, \mathrm{H}-8), 2.81(1 \mathrm{H}, b r d, J=12.4 \mathrm{~Hz}$, $\mathrm{H}-10), 1.97(1 \mathrm{H}, d d, J=12.6,2.2 \mathrm{~Hz}, \mathrm{H}-12 \alpha), 2.74(1 \mathrm{H}, d, J=12.6 \mathrm{~Hz}, \mathrm{H}-12 \beta), 1.38(1 \mathrm{H}, d d, J=9.9$, $2.5 \mathrm{~Hz}, \mathrm{H}-8 \alpha), 1.77(1 \mathrm{H}, d, J=12.4 \mathrm{~Hz}, \mathrm{H}-14 \beta), 5.84(1 \mathrm{H}, d d, J=17.3,10.7 \mathrm{~Hz}, \mathrm{H}-15), 4.95(1 \mathrm{H}, d d$, $J=10.7,0.8 \mathrm{~Hz}, \mathrm{H}-16), 4.97(1 \mathrm{H}, d d, J=17.3,0.8 \mathrm{~Hz}, \mathrm{H}-16), 0.99$ (3H, $s, \mathrm{H}-17), 1.22(3 \mathrm{H}, s, \mathrm{H}-18)$, $1.10(3 \mathrm{H}, s, \mathrm{H}-19), 1.02(3 \mathrm{H}, s, \mathrm{H}-20) ;{ }^{13} \mathrm{C}-\mathrm{NMR}\left(100 \mathrm{MHz}, \mathrm{CDCl}_{3}\right): \delta 214.6,164.8,147.9,144.5$, $135.8,132.8,132.6,130.0,128.2,122.5,117.9,110.2,80.0,49.0,48.4,41.6,41.2,38.4,38.3,37.9$, $28.9,26.7,25.0,24.6,23.5,23.1,12.6$.

\section{Conclusions}

A new rosane diterpenoid $\mathbf{3}$ was isolated from the unidentified Argentine liverwort Anastrophyllum species, together with a known rosane diterpenoid 4 and an aromadendrane sesquiterpenoid $\mathbf{5}$. The known bibenzyls 10 and 11 and sesquiterpene lactones 6-9 were isolated from Argentine Radula voluta and Frullania brasiliensis.

\section{Acknowledgements}

We thank A. Bardón (Tucumán National University, Argentina) for the collection of the liverworts and S.R. Gradstein (University of Göttingen, Germany) for the identification of their species. Thanks are also due to M. Tanaka (TBU) and Miss Y. Okamoto (TBU) for measurements of $600 \mathrm{MHz}$ NMR spectra and mass spectra, and N. Minakami and Miss H. Morinaga for their technical assistance. 


\section{References and Notes}

1. Asakawa, Y. Chemical constituents of the Hepaticae. In Progress in the Chemistry of Organic Natural Products, Herz, W., Grisebach, H., Kirby, G.W., Eds.; Springer-Verlag: Wien, Austria, 1982; Volume 42, pp. 1-269.

2. Asakawa, Y. Chemical constituents of the Bryophytes. In Progress in the Chemistry of Organic Natural Products, Herz, W., Kirby, G.W., Moore, R.E., Steglich, W., Tamm, Ch., Eds.; Springer-Verlag: Wien, Austria, 1995; Volume 65, pp. 1-618.

3. Asakawa, Y.; Toyota, M.; Nagashima, F.; Hashimoto, T. Chemical constituents of selected Japanese and New Zealand liverworts. Nat. Prod. Commun. 2008, 3, 289-300.

4. Nagashima, F.; Kuba, Y.; Ogata, A.; Asakawa, Y. Sesqui- and diterpenoids from three New Zealand liverworts Bazzania novae-zelandiae, Gackstroemia sp. and Dendromastigophora sp. Nat. Prod. Res. 2010, 24, 68-75.

5. Matsuo, A.; Nakayama, M.; Sato, S.; Nakamoto, T.; Uto, S.; Hayashi, S. (-)-Maalioxide and (+)-cyclocolorenone, enantiomeric sesquiterpenoids from the liverwort, Plagiochila acanthophylla subsp. japonica. Experientia 1974, 30, 321-322.

6. Feld, H.; Zapp, J.; Becker, H. Secondary metabolites from the liverwort Tylimanthus renifolius. Phytochemistry 2003, 64, 1335-1340.

7. Bardón, A.; Mitre, G.B.; Kamiya, N.; Toyota, M.; Asakawa, Y. Eremophilanolides and other constituents from the Argentine liverwort Frullania brasiliensis. Phytochemistry 2002, 59, 205-213.

8. Asakawa, Y.; Muller, J.-C.; Ourisson, G.; Foussereau, J.; Ducombs, G. Nouvelles lactones sesquiterpéniques de Frullania (Hépaticae). Isolement, structures, propriétés allergisantes. Bull. Soc. Chim. France 1976, 1465-1466.

9. Tori, M.; Miyazaki, N.; Kondo, K.; Taira, Z.; Asakawa, Y. Nepalensolide A, Novel sesquiterpene lactone from the liverwort Frullania nepalensis. Compound breaking the Samek rule. A study by NOE and X-ray. Chem. Lett. 1990, 2115-2116.

10. Asakawa, Y.; Toyota, M.; Takemoto, T. Seven bibenzyls and a dihydrochalcone from Radula variabilis. Phytochemistry 1978, 17, 2005-2010.

11. Crombie, L.W.; Crombie, W.M.L.; Firth, D.F. Synthesis of bibenzyl cannabinoids, hybrids of two biogenetic series found in Cannabis sativa. J. Chem. Soc. Perkin Trans. 1 1988, 1263-1270.

12. Asakawa, Y.; Kondo, K.; Tori, M.; Hashimoto, T.; Ogawa, S. Prenyl bibenzyls from the liverwort Radula kojana. Phytochemistry 1991, 30, 219-234.

13. Beyer, J.; Becker, H.; Toyota, M.; Asakawa, Y. Diterpenoids with a novel skeleton from the liverwort Anastrophyllum minutum. Phytochemistry 1987, 26, 1085-1089.

14. Zapp, J.; Burkhardt, G.; Becker, H. Sphenolobane and fusicoccane diterpenoids from the liverwort Anastrophyllum aurztum. Phytochemistry 1994, 37, 787-793.

15. Buchanan, M.S.; Connolly, J.D.; Rycroft, D.S. Sphenolobane diterpenoids from the liverwort Anastrophyllum donnianum. Phytochemistry 1996, 43, 1297-1301.

16. Asakawa, Y. Chemosystematics of Hepaticae. Phytochemistry 2004, 65, 623-669.

17. Kraut, L.; Mues, R.; Zinsmeister, H.D. Prenylated bibenzyl derivatives from Lethocolea glossophylla and Radula voluta. Phytochemistry 1997, 45, 1249-1255. 
18. Godin, P. A new spray reagent for paper chromatography of polyols and cetoses. Nature (London) 1954, 174, 134.

Sample Availability: Samples of the compounds 5-10 are available from the authors.

(C) 2011 by the authors; licensee MDPI, Basel, Switzerland. This article is an open access article distributed under the terms and conditions of the Creative Commons Attribution license (http://creativecommons.org/licenses/by/3.0/). 